Check for updates

Cite this: RSC Adv., 2017, 7, 25634

\title{
A new near-infrared ratiometric fluorescent probe for hydrazine $\uparrow$
}

\author{
Yangyang $\mathrm{He}^{\mathrm{ab}}{ }^{\mathrm{b}}$ Zhanxian Li, ${ }^{\mathrm{b}}$ Bingjie Shi, ${ }^{\mathrm{b}}$ Zhen An, ${ }^{\mathrm{b}}$ Mingming $\mathrm{Yu},{ }^{\mathrm{D}}{ }^{\mathrm{b}}$ Liuhe Wei $^{\mathrm{b}}$ \\ and Zhonghai $\mathrm{Ni}$ (D) *a
}

It is important to develop fluorescent probes for rapid, selective, and sensitive detection of highly toxic hydrazine in both environmental and biological science. In this text, under mild conditions, a novel nearinfrared (NIR) ratiometric and on-off fluorescent probe 1 was synthesized based on hemicyanine and coumarin derivatives, which can detect hydrazine with high selectivity and anti-interference over other amines, biological species, anions and metal ions. The limit of quantification (LOQ) value was $0-400 \mu \mathrm{M}$ and the detection limit could be as low as $560 \mathrm{nM}$.

Received 15th April 2017

Accepted 8th May 2017

DOI: $10.1039 / c 7 r a 04270 a$

rsc.li/rsc-advances

biomolecules due to its simplicity, high sensitivity, and

\section{Introduction}

As an important biochemical reagent and highly reactive base, hydrazine is extensively used in the chemical, pharmaceutical and agricultural industries. ${ }^{1-3}$ Due to its flammable and detonable characteristics, hydrazine is often applied in rocketpropulsion systems and missile systems. ${ }^{4}$ However, hydrazine is a class of highly toxic and pollutant compound, which can potentially lead to serious environmental contamination during its manufacture, use, transport and disposal. In addition, hydrazine is highly toxic and may affect the liver, lungs, kidneys and human central nervous system. ${ }^{5-8}$ As a result, the World Health Organization has classified hydrazine as possible cancer-causing environmental contaminants, and Occupational Safety and Health Administration (OSHA) has recommended the threshold limit value of hydrazine must be lower than 1 ppm. ${ }^{9}$ Therefore, the development of sensitive, selective and reliable methods for trace hydrazine has gained increasing attention.

To date, several conventional analytical techniques, including chromatography-mass spectrometry, ${ }^{10-12}$ spectrophotometry ${ }^{13}$ and electrochemical methods ${ }^{14-18}$ have been exploited to measure hydrazine. But most of the methods mentioned previously are costly, complicated and time consuming for realtime and on-site analysis. Thus, simple, selective and sensitive methods for qualitative and quantitative detection of hydrazine are in great need. In recent years, fluorescence analysis system has been widely used to detect metal ions, anions and

${ }^{a}$ School of Chemical Engineering and Technology, China University of Mining and Technology, Xuzhou 221116, Jiangsu Province, China. E-mail: nizhonghai@cumt. edu.cn

${ }^{b}$ College of Chemistry and Molecular Engineering, Zhengzhou University, Zhengzhou 450001, China

$\dagger$ Electronic supplementary information (ESI) available: Synthesis procedure and spectral data. See DOI: 10.1039/c7ra04270a instantaneous response. ${ }^{19-32}$ However, available fluorescent probes for hydrazine are still very limited and most of them are turn-on types. ${ }^{33-41}$

It is obvious that many factors influence the emission intensity, such as the illumination intensity and optical path length, which are prone to disturbance in quantitative detection. A ratiometric approach can eliminate the effects of these factors and realize more effective quantitative detection through measuring the ratio of fluorescence intensities at two different wavelengths. ${ }^{42}$ In addition, when fluorescent intensity based probes are used in complicated biosystems, the detection are influenced by the probe concentration, autofluorescence, and instrumental factors. ${ }^{43,44}$ Ratiometric sensing is highly recommended because this property makes it feasible to evaluate the analytes more accurately with minimization of the background signal. By comparison, based on absorption properties of the ground state, color changes are more suitable for direct observation with the naked eye. ${ }^{45}$ Therefore it is of great interest to design ratiometric fluorescent and colorimetric probes for hydrazine. ${ }^{46-52}$

On the other hand, the spectral absorption range of biological tissues and blood samples mainly centered from 200 to $650 \mathrm{~nm}$, and the extinction coefficients of these organisms are relatively large, which will cause considerable interference on the optical imaging in the visible light range. Therefore, fluorescent imaging in the NIR light range (650 to $900 \mathrm{~nm}$ ) will be ideal for vivo imaging. NIR fluorescence can not only reduce the ratio of signal to noise, but also can achieve the optimal imaging with the deep penetration ability into the tissue.

In this paper, a highly sensitive, colorimetric and NIR ratiometric fluorescent probe $\mathbf{1}$ was synthesized, which can quantitatively detect hydrazine. The detection limit on fluorescence response of the probe can be as low as $560 \mathrm{nM}$. 


\section{Results and discussions}

\section{Hydrazine recognizing properties of probe 1}

To study the recognizing properties of $\mathbf{1}$ toward hydrazine, UV-vis and fluorescence titration experiments (Fig. 1 and 2) were conducted with $0.1 \mathrm{M}$ hydrazine water solution in aqueous solution of $1\left(1.0 \times 10^{-5} \mathrm{M}, V_{\text {HEPES }} / V_{\text {DMSO }}=5 / 5, \mathrm{pH} 7.40\right)$. Upon addition of hydrazine, the peak at $584 \mathrm{~nm}$ in the UV-vis spectrum decreased gradually while a new band developed at $418 \mathrm{~nm}$, and then, the band reached the maxima at 100 equiv. of hydrazine (Fig. 1a). As demonstrated in Fig. 1b, in the concentration range of $350 \mu \mathrm{M}$ and $1 \mathrm{mM}$, the absorbance ratio of $A_{418}$ to $A_{584}\left(A_{418} / A_{584}\right)$ is in good linear relationship with hydrazine concentration. From the linear calibration graph with the absorbance titration experiment, the detection limit of probe $\mathbf{1}$ for hydrazine was found to be about 3.2 $\mu \mathrm{M}$ based on signal-to-noise ratio $(\mathrm{S} / \mathrm{N})=3 .^{53,54}$ Fig. S1 in ESI $\dagger$ indicate the relationship of the absorbance ratio of $A_{418} / A_{584}$ with the concentration of hydrazine. The solution color of 1 changed by degrees from blue to pale yellow in the presence of different concentrations of hydrazine (Fig. 1c), implying that compound 1 can be served as a highly sensitive 'naked-eye' probe for hydrazine in aqueous solution.

As shown in Fig. 2, upon excitation at $450 \mathrm{~nm}$, there were two emission peaks centered at $510 \mathrm{~nm}$ and $660 \mathrm{~nm}$ in the emission spectrum of compound $1\left(1.0 \times 10^{-5} \mathrm{M}, V_{\mathrm{HEPES}} / V_{\mathrm{DMSO}}=5 / 5, \mathrm{pH}\right.$ 7.40). Upon gradual addition of hydrazine, the emission at $660 \mathrm{~nm}$ decreased while the emission at $510 \mathrm{~nm}$ increased with a clear isosbestic point at $633 \mathrm{~nm}$ observed (Fig. 2a). Upon excitation at $580 \mathrm{~nm}$, its emission spectrum displayed the characteristic emission band of cyanine centered at $660 \mathrm{~nm}$, which underwent a decrease of about 10 times with the concentration of hydrazine increasing from 0 to 100 equiv. (Fig. 2b). Fig. S2 and S3 in ESI $†$ indicate the relationship of the emission intensity ratio of $I_{510}$ to $I_{660}\left(I_{510} / I_{660}\right)$ and the emission intensity at $660 \mathrm{~nm}\left(I_{660}\right)$ with the concentration of hydrazine
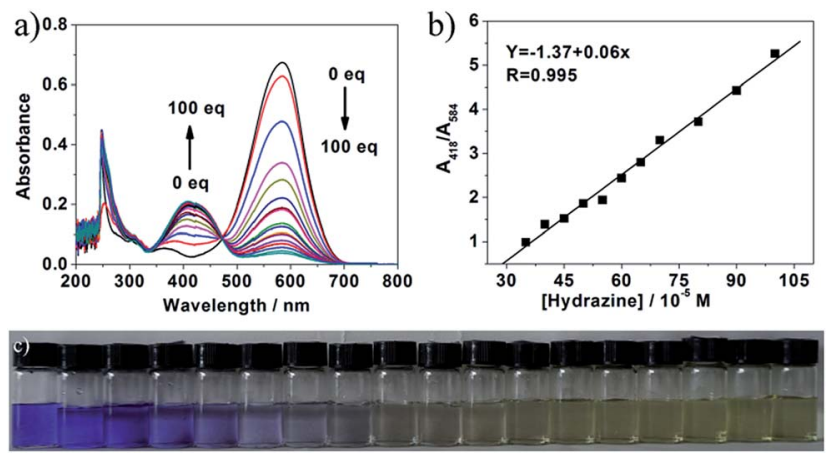

Fig. 1 Absorption spectra of $1\left(1.0 \times 10^{-5} \mathrm{M}, V_{\text {HEPES }} / V_{\text {DMSO }}=5 / 5, \mathrm{pH}\right.$ 7.40) upon titration of hydrazine water solution (0-100 equiv. to 1 ) (a). The relationship of absorbance ratio of $A_{418} / A_{584}$ with the concentration of hydrazine (b). Photographs of compound $1\left(1.0 \times 10^{-5} \mathrm{M}\right.$, $V_{\text {HEPES }} / V_{\text {DMSO }}=5 / 5, \mathrm{pH} 7.40$ ) upon addition of hydrazine at various concentrations $\left(0 \mathrm{M}, 5 \times 10^{-5} \mathrm{M}, 10 \times 10^{-5} \mathrm{M}, 15 \times 10^{-5} \mathrm{M}, 20 \times\right.$ $10^{-5} \mathrm{M}, 25 \times 10^{-5} \mathrm{M}, 30 \times 10^{-5} \mathrm{M}, 35 \times 10^{-5} \mathrm{M}, 40 \times 10^{-5} \mathrm{M}, 45 \times$ $10^{-5} \mathrm{M}, 50 \times 10^{-5} \mathrm{M}, 55 \times 10^{-5} \mathrm{M}, 60 \times 10^{-5} \mathrm{M}, 65 \times 10^{-5} \mathrm{M}, 70 \times$ $10^{-5} \mathrm{M}, 75 \times 10^{-5} \mathrm{M}, 80 \times 10^{-5} \mathrm{M}, 90 \times 10^{-5} \mathrm{M}, 100 \times 10^{-5} \mathrm{M}$ from left to right) in water in daylight (c). The reaction time was 24 hours.
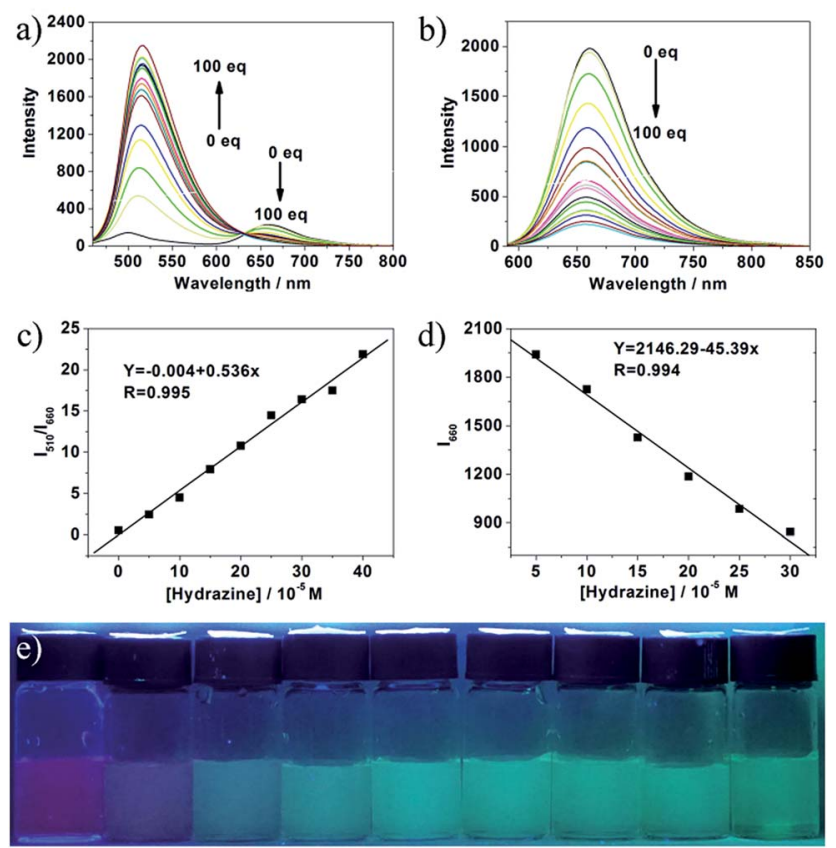

Fig. 2 Emission spectra of compound $1\left(1.0 \times 10^{-5} \mathrm{M}, V_{\text {HEPES }} / V_{\text {DMSO }}=\right.$ $5 / 5, \mathrm{pH} 7.40)$ upon titration of hydrazine water solution (0-100.0 equiv. to 1) with excitation at $450 \mathrm{~nm}$ (a) and $580 \mathrm{~nm}$ (b). The linearity of emission intensity ratio of $I_{510} / /_{660}$ (c) and the emission intensity at $660 \mathrm{~nm}\left(I_{660}\right)$ (d) with hydrazine concentration increasing respectively. (e) Photographs of compound $1\left(1.0 \times 10^{-5} \mathrm{M}, V_{\text {HEPES }} / V_{\text {DMSO }}=5 / 5, \mathrm{pH}\right.$ 7.40) upon addition of hydrazine at various concentrations $(0 M, 5 \times$ $10^{-5} \mathrm{M}, 10 \times 10^{-5} \mathrm{M}, 20 \times 10^{-5} \mathrm{M}, 30 \times 10^{-5} \mathrm{M}, 40 \times 10^{-5} \mathrm{M}, 50 \times$ $10^{-5} \mathrm{M}, 60 \times 10^{-5} \mathrm{M}, 70 \times 10^{-5} \mathrm{M}$, from left to right) in water under a UV lamp $(365 \mathrm{~nm})$. The reaction time was 24 hours.

respectively. As demonstrated in Fig. 2c and d, in the concentration range of $0-400 \mu \mathrm{M}$ and $50-300 \mu \mathrm{M}, I_{510} / I_{660}$ and $I_{660}$ were in good linear relationship with hydrazine concentration respectively, implying that hydrazine can be quantitatively detected in a wider concentration range in dual-fluorescence mode. From the linear calibration graphs with the fluorescence titration experiments (Fig. $2 \mathrm{c}$ and d), the detection limit of probe 1 for hydrazine was found to be about $560 \mathrm{nM}$ based on signal-tonoise ratio $(\mathrm{S} / \mathrm{N})=3$, which was sufficiently low for the detection of hydrazine. Further experiments indicated that the fluorescence color of probe $\mathbf{1}$ aqueous solution changed from purple to green under excitation of $365 \mathrm{~nm}$ light (Fig. 2e). These results led us to conclude that 1 could be an effective ratiometric and on-off fluorescent probe for hydrazine. In the previous reported work, ${ }^{55}$ an organic molecular probe was reported, which had the same chemical structure and could detect $\mathrm{SO}_{3}{ }^{2-}$ and $\mathrm{HSO}_{3}{ }^{-}$. The different recognition results may be ascribed to the different solution. In addition, the group of professor Feng in Central China Normal University has reported some hemicyanine derivatives, which have similar chemical structures as that herein and can detect both $\mathrm{SO}_{3}{ }^{2-}$ and $\mathrm{HSO}_{3}{ }^{-56-58}$ Such strange results make us have interest to work hard to clarify the difference in properties of similar organic dyes.

The recognition mechanism was studied by mass spectrometry. For probe $\mathbf{1}$, a characteristic peak at $m / z=451.2385$ 
was found which corresponds to the species [M - I] (Fig. S4 in ESI $\dagger$ ), whilst after reaction with hydrazine, the peak at 451.2385 disappeared and two new peaks appeared at $m / z=224.1440$ and 261.1413, which are corresponding to compounds $2[\mathrm{M}-\mathrm{I}]$ and 1-NHNH $\mathbf{N}_{2}[\mathrm{M}+\mathrm{H}]$ (Fig. S5 in ESI $\dagger$ ). Such mass spectral data indicating the decomposition of probe $\mathbf{1}$ and the formation of new compounds 2 and 1-NHNH 2 (Scheme 1).

\section{$\mathrm{pH}$ range in application of probe 1 toward hydrazine}

The $\mathrm{pH}$ is an important factor affecting the reaction of probe $\mathbf{1}$ with hydrazine. To investigate the $\mathrm{pH}$ effect, the fluorescence of $10.0 \mu \mathrm{M}$ probe 1 in the absence and presence of $1 \mathrm{mM}$ hydrazine were examined at $\mathrm{pH}$ range from 4.0 to 10.0. From Fig. 3, we find that fluorescence ratio of probe 1 showed no apparent change with the $\mathrm{pH}$ changing from 6.0 to 10.0. However, the fluorescence ratio of $\mathbf{1}-\mathbf{N H N H}_{2}$ exhibited obvious change when the $\mathrm{pH}$ increased to 10.0. Such result implies that probe $\mathbf{1}$ is able to detect hydrazine in a relatively wide $\mathrm{pH}$ range.

\section{The selectivity study of probe 1 for hydrazine}

To evaluate the selectivity of probe $\mathbf{1}$ for hydrazine, various species including various amines (thiourea, triethylamine, $\mathrm{N}, \mathrm{N}$ diisopropylethylamine, ammonia water, carbamide, aniline), some nucleophilic species (Tyr, Ala, $\mathrm{H}_{2} \mathrm{O}_{2}$, Pro, Cys, Met, Lys, Phe, Thr, Ile, Trp, Ser, Val), various metal ions $\left(\mathrm{Na}^{+}, \mathrm{Mg}^{2+}, \mathrm{K}^{+}\right.$, $\left.\mathrm{Ca}^{2+}, \mathrm{Cd}^{2+}, \mathrm{Mn}^{2+}\right)$ and anions $\left(\mathrm{C}_{2} \mathrm{O}_{4}{ }^{2-}, \mathrm{H}_{2} \mathrm{PO}_{4}{ }^{-}, \mathrm{SO}_{3}{ }^{2-}, \mathrm{HSO}_{3}{ }^{-}\right.$,
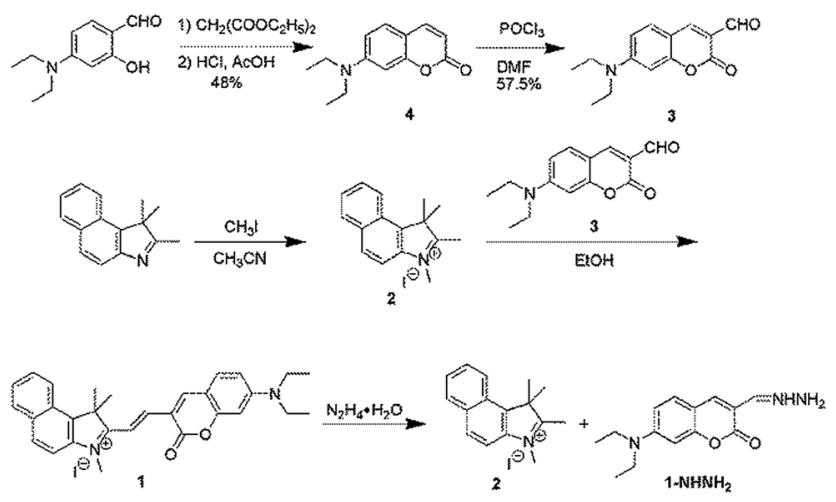

Scheme 1 Synthetic route of probe 1 and the proposed mechanism of the response of 1 to hydrazine.
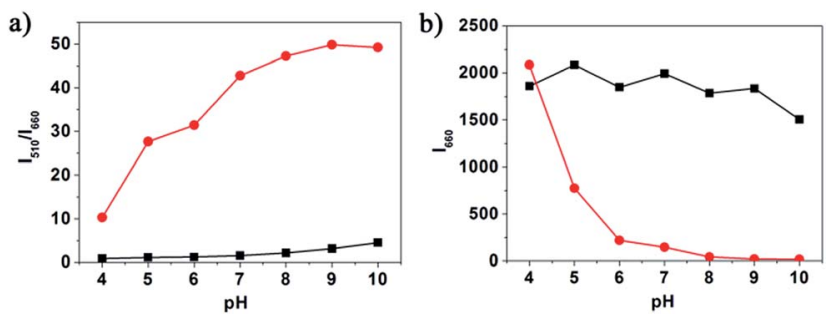

Fig. 3 Fluorescence change of $1\left(1.0 \times 10^{-5} \mathrm{M}, V_{\text {HEPES }} / V_{\text {DMSO }}=5 / 5\right)$ before (black line) and after (red line) addition of hydrazine $(1 \mathrm{mM})$ with different $\mathrm{pH}$ with excitation at $450 \mathrm{~nm}$ (a) and $580 \mathrm{~nm}$ (b). The reaction time was 24 hours.
$\mathrm{N}_{3}{ }^{-}, \mathrm{Cl}^{-}, \mathrm{Br}^{-}, \mathrm{I}^{-}, \mathrm{ClO}_{3}{ }^{-}, \mathrm{ClO}_{4}{ }^{-}, \mathrm{NO}_{3}{ }^{-}, \mathrm{SO}_{4}{ }^{2-}$ ) were tested. As shown in Fig. 4, green bars of Fig. 5, 6, and 7, only the introduction of hydrazine to the probe 1 solution induced a significant fluorescence change. In the same condition, other tested species mentioned above did not induce any obvious fluorescence change to the probe 1 solution (Fig. 4, green bars of Fig. 5,
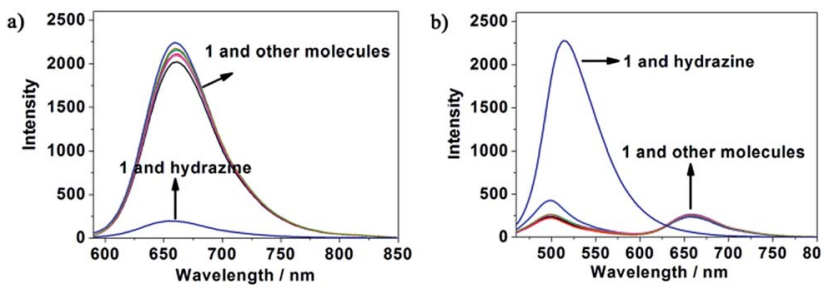

Fig. 4 Emission spectra of $1\left(1.0 \times 10^{-5} \mathrm{M}, V_{\text {HEPES }} / V_{\text {DMSO }}=5 / 5, \mathrm{pH}\right.$ 7.40) upon addition of 100 equiv. of various species (hydrazine, thiourea, triethylamine, $\mathrm{N}, \mathrm{N}$-diisopropylethylamine, ammonia water, carbamide, aniline) with excitation at $450 \mathrm{~nm}$ (a) and $580 \mathrm{~nm}$ (b).
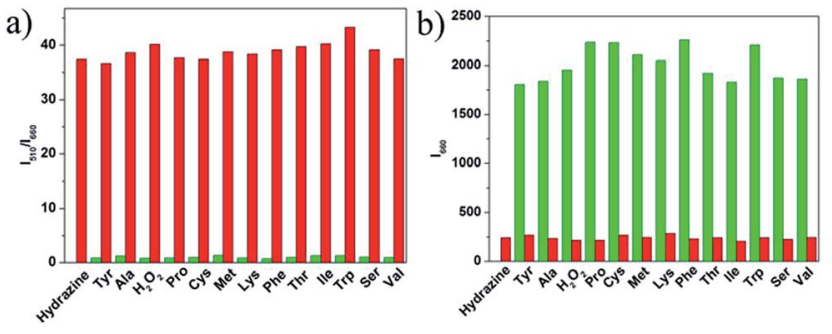

Fig. 5 Fluorescence responses of $1\left(1.0 \times 10^{-5} \mathrm{M}, V_{\text {HEPES }} / V_{\text {DMSO }}=5 /\right.$ $5, \mathrm{pH} 7.40$ ) upon addition of different species (100 equiv. of species relative to 1) (green bars) with excitation at $450 \mathrm{~nm}$ (a) and $580 \mathrm{~nm}$ (b), and fluorescence changes of the mixture of 1 and hydrazine $(1.0 \times$ $10^{-3} \mathrm{M}$ in water) after addition of an excess of the indicated species (100 equiv. relative to 1) (red bars) with excitation at $450 \mathrm{~nm}$ (a) and $580 \mathrm{~nm}$ (b). $I_{510}$ and $I_{660}$ represent the emission intensity at $510 \mathrm{~nm}$ and $660 \mathrm{~nm}$. I660 means the emission intensity at $660 \mathrm{~nm}$. The species used were Tyr, Ala, $\mathrm{H}_{2} \mathrm{O}_{2}$, Pro, Cys, Met, Lys, Phe, Thr, lle, Trp, Ser, Val. The reaction time was 24 hours.
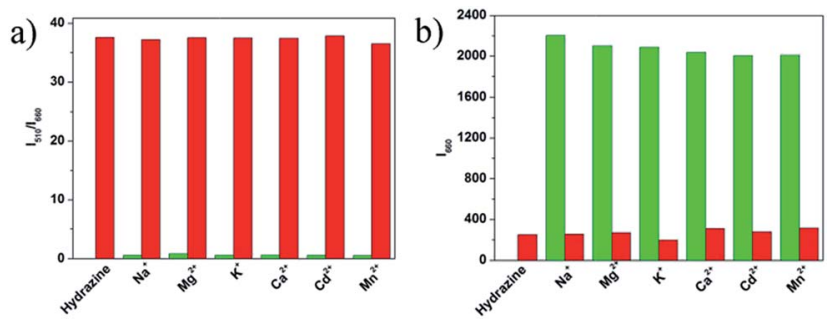

Fig. 6 Fluorescence responses of $1\left(1.0 \times 10^{-5} \mathrm{M}, V_{\text {HEPES }} / V_{\text {DMSO }}=5 /\right.$ $5, \mathrm{pH}$ 7.40) upon addition of different species (100 equiv. of species relative to 1) (green bars) with excitation at $450 \mathrm{~nm}$ (a) and $580 \mathrm{~nm}$ (b), and fluorescence changes of the mixture of 1 and hydrazine $(1.0 \times$ $10^{-3} \mathrm{M}$ in water) after addition of an excess of the indicated species (50 equiv. relative to 1) (red bars) with excitation at $450 \mathrm{~nm}$ (a) and $580 \mathrm{~nm}$ (b). $I_{510}$ and $I_{660}$ represent the emission intensity at $510 \mathrm{~nm}$ and $660 \mathrm{~nm}$. Intensity means the emission intensity at $660 \mathrm{~nm}$. The species used were $\mathrm{Na}^{+}, \mathrm{Mg}^{2+}, \mathrm{K}^{+}, \mathrm{Ca}^{2+}, \mathrm{Cd}^{2+}$, and $\mathrm{Mn}^{2+}$. The reaction time was 24 hours. 


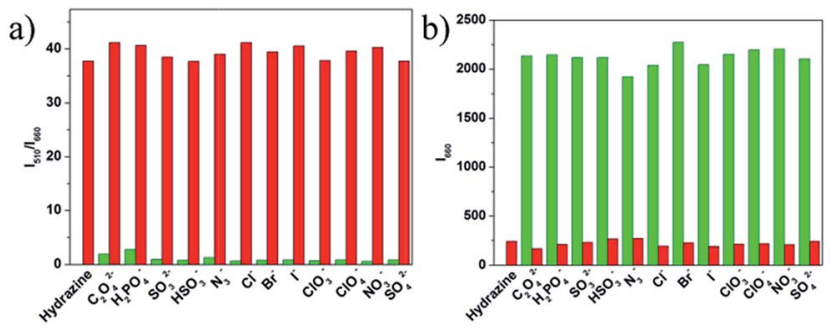

Fig. 7 Fluorescence responses of $1\left(1.0 \times 10^{-5} \mathrm{M}, V_{\text {HEPES }} / V_{\text {DMSO }}=5 / 5\right.$, $\mathrm{pH}$ 7.40) upon addition of different species (100 equiv. of species relative to 1) (green bars) with excitation at $450 \mathrm{~nm}$ (up) and $580 \mathrm{~nm}$ (down), and fluorescence changes of the mixture of 1 and hydrazine $\left(1.0 \times 10^{-3} \mathrm{M}\right.$ in water) after addition of an excess of the indicated species (50 equiv. relative to 1 ) (red bars) with excitation at $450 \mathrm{~nm}$ (up) and $580 \mathrm{~nm}$ (down). $I_{510}$ and $I_{660}$ represent the emission intensity at $510 \mathrm{~nm}$ and $660 \mathrm{~nm}$. Intensity means the emission intensity at $660 \mathrm{~nm}$. The species used were $\mathrm{C}_{2} \mathrm{O}_{4}{ }^{2-}, \mathrm{H}_{2} \mathrm{PO}_{4}^{-}, \mathrm{SO}_{3}{ }^{2-}, \mathrm{HSO}_{3}{ }^{-}, \mathrm{N}_{3}^{-}, \mathrm{Cl}^{-}, \mathrm{Br}^{-}$, $I^{-}, \mathrm{ClO}_{3}{ }^{-}, \mathrm{ClO}_{4}^{-}, \mathrm{NO}_{3}{ }^{-}$, and $\mathrm{SO}_{4}{ }^{2-}$. The reaction time was 24 hours.

6, 7, S6 and S7 in ESI $\dagger$ ). Such results approved the remarkably high selectivity of $\mathbf{1}$ towards hydrazine over other competitive species at physiological $\mathrm{pH} 7.40$.

\section{The anti-disturbance effect study of 1 for hydrazine detection}

To further assess its utility as a hydrazine-selective fluorescent probe, its fluorescence spectral response to hydrazine in the presence of other species mentioned above was also tested (red bars of Fig. 5, 6, 7, S6 and S7 in ESI $\dagger$ ). The results demonstrated that all of the selected species have no interference in the detection of hydrazine. This result strongly indicates that compound 1 could be an excellent fluorescent probe towards hydrazine with strong anti-interference ability.

\section{Experimental section}

\section{Materials and methods}

4-Diethylaminosalicylaldehyde, diethylmalonate, piperidine, $\mathrm{HCl}$, glacial acetic acid, $\mathrm{POCl}_{3}$, 1,1,2-trimethylbenzo[e]indolenine, $\mathrm{CH}_{3} \mathrm{I}, \mathrm{NaCl}, \mathrm{MgCl}_{2}, \mathrm{KCl}, \mathrm{CaCl}_{2}, \mathrm{MnCl}_{2}, \mathrm{Cd}\left(\mathrm{NO}_{3}\right)_{2}, \mathrm{Na}_{2} \mathrm{SO}_{4}$, $\mathrm{Na}_{2} \mathrm{SO}_{3}, \mathrm{KNO}_{3}, \mathrm{Na}_{2} \mathrm{~N}_{3}, \mathrm{NaI}, \mathrm{NaHSO}_{3}, \mathrm{NaH}_{2} \mathrm{PO}_{4}, \mathrm{NaClO}_{4}, \mathrm{NaClO}_{3}$, $\mathrm{NaCl}, \mathrm{Na}_{2} \mathrm{C}_{2} \mathrm{O}_{4}, \mathrm{NaBr}$, thiourea, triethylamine, $N, N$-diisopropylethylamine, ammonia water, carbamide, aniline, Tyr, Ala, $\mathrm{H}_{2} \mathrm{O}_{2}$, Pro, Cys, Met, Lys, Phe, Thr, Ile, Trp, Ser, and Val. All commercial grade chemicals and solvents were purchased and were used without further purification. Mass spectra were obtained on high resolution mass spectrometer (IonSpec4.7 Tesla FTMS-MALDI/DHB). ${ }^{1} \mathrm{H}$ and ${ }^{13} \mathrm{C}$ NMR spectra were recorded on a Bruker 400 NMR spectrometer. Chemical shifts were reported in parts per million using tetramethylsilane (TMS) as the internal standard.

All spectral characterizations were carried out in HPLC-grade solvents at $20{ }^{\circ} \mathrm{C}$ within a $10 \mathrm{~mm}$ quartz cell. UV-vis absorption spectra were measured with a TU-1901 double-beam UV-vis spectrophotometer. Fluorescence spectroscopy was determined on a Hitachi F-4600 spectrometer.

Probe 1 was synthesized according to Scheme 1.

\section{Synthesis of compound 4}

4-Diethylaminosalicylaldehyde $(0.48 \mathrm{~g}, 2.5 \mathrm{mmol})$, diethylmalonate $(750 \mu \mathrm{L}, 5 \mathrm{mmol})$ and piperidine $(250 \mu \mathrm{L})$ were combined in absolute ethanol $(15 \mathrm{~mL})$ and stirred for 6 hours under reflux conditions. Ethanol was evaporated under reduced pressure, and then concentrated $\mathrm{HCl}(10 \mathrm{~mL})$ and glacial acetic acid $(10 \mathrm{~mL})$ were added to hydrolyze the reaction with stirring for another 10 hours. The solution was cooled to room temperature and poured into $15 \mathrm{~mL}$ ice water. $\mathrm{NaOH}$ solution (40\%) was added dropwise to modulate $\mathrm{pH}$ of the solution to $\sim 5$, and a pale precipitate was formed immediately. After stirring for 30 minutes, the mixture was filtered, washed with water, dried and recrystallized with toluene. And then the final product 4 was purified with the yield of $48 \%$ by silica gel column chromatography using dichloromethane as eluent. Characterization of 4: ${ }^{1} \mathrm{H}$ NMR (400 MHz, $\mathrm{CDCl}_{3}-d_{6}$, TMS) (Fig. S8 in ESI $\dagger$ ): $\delta_{\mathrm{H}} 7.54(\mathrm{~d}, 1 \mathrm{H}), 7.27(\mathrm{t}, 1 \mathrm{H}), 6.50(\mathrm{~m}, 1 \mathrm{H}), 6.50(\mathrm{~d}, 1 \mathrm{H}), 6.03(\mathrm{~d}$, $1 \mathrm{H}), 3.42(\mathrm{~m}, 4 \mathrm{H}), 1.24(\mathrm{t}, 6 \mathrm{H}) .{ }^{13} \mathrm{C}$ NMR (100 MHz, $\left.\mathrm{CDCl}_{3}-d_{6}\right)$ (Fig. S9† in ESI $\dagger$ ): $\delta_{\mathrm{C}} 12.44,44.82,97.53,108.29,108.67,109.19$, $128.77,143.70,150.66,156.74,162.28$.

\section{Synthesis of compound 3}

Fresh distilled DMF (1 mL) was added dropwise to $\mathrm{POCl}_{3}(1 \mathrm{~mL})$ at $20-50{ }^{\circ} \mathrm{C}$ with $\mathrm{N}_{2}$ atmosphere and stirred for 30 minutes to yield a red solution. This solution was combined with a portion of $4(0.2543 \mathrm{~g}, 1.2 \mathrm{mmol}$, dissolved in $2 \mathrm{~mL} \mathrm{DMF})$ to yield a scarlet suspension. The mixture was stirred at $60{ }^{\circ} \mathrm{C}$ for 12 hours and then poured into $15 \mathrm{~mL}$ ice water. $\mathrm{NaOH}$ solution $(20 \%)$ was added to adjust the $\mathrm{pH}$ of the mixture to yield large amount of precipitate. The crude product was filtered, thoroughly washed with water, dried and recrystallized in absolute ethanol to give $3(1.20 \mathrm{~g}, 4.89 \mathrm{mmol})$. The final product 3 was purified $(57.5 \%$ yield) by silica gel column using chromatography using ethanol/dichloromethane $(1 / 3 \mathrm{v} / \mathrm{v})$ as eluent. ${ }^{1} \mathrm{H}$ NMR (400 MHz, $\mathrm{CDCl}_{3}-d_{6}$, TMS) (Fig. S10 in ESI $\dagger$ ): $\delta_{\mathrm{H}} 10.13$ (s, $1 \mathrm{H}), 8.26(\mathrm{~s}, 1 \mathrm{H}), 7.43(\mathrm{~d}, 1 \mathrm{H}), 6.67(\mathrm{~m}, 1 \mathrm{H}), 6.51(\mathrm{~d}, 1 \mathrm{H}), 3.50(\mathrm{~m}$, $4 \mathrm{H}), 1.27$ (t, 6H). ${ }^{13} \mathrm{C}$ NMR (100 $\mathrm{MHz} \mathrm{CDCl}_{3}-d_{6}$ ) (Fig. S11 in $\mathrm{ESI} \dagger): \delta_{\mathrm{C}} 12.46,29.70,45.29,97.15,108.23,110.20,132.52$, 145.37, 153.47, 158.93, 161.89, 187.92.

\section{Synthesis of compound 2}

1,1,2-Trimethylbenzo[e]indolenine (313.51 $\mathrm{mg}, 1.5 \mathrm{mmol})$ and $\mathrm{CH}_{3} \mathrm{I}(2.5 \mathrm{~mL}, 7.5 \mathrm{mmol})$ were dissolved in $10 \mathrm{~mL}$ acetonitrile. The mixture was refluxed for 12 hours and then allowed to cool to room temperature. By filtration of the above mixture, the solid was obtained as product 2 (393 $\mathrm{mg}, 1.17 \mathrm{mmol})$ in $78 \%$ yield. ${ }^{1} \mathrm{H}$ NMR (400 MHz, DMSO- $d_{6}$, TMS) (Fig. S12 in ESI $\dagger$ ): $\delta_{\mathrm{H}} 8.39$ (d, $1 \mathrm{H}), 8.29$ (d, 1H), 8.21 (d, 1H), $8.10(\mathrm{~d}, 1 \mathrm{H}), 7.75(\mathrm{~m}, 2 \mathrm{H}), 4.11(\mathrm{~s}$, $3 \mathrm{H}), 2.88(\mathrm{~s}, 3 \mathrm{H}), 1.76(\mathrm{~s}, 6 \mathrm{H}) .{ }^{13} \mathrm{C}$ NMR $\left(100 \mathrm{MHz}, \mathrm{DMSO}-d_{6}\right)$ (Fig. S13 in ESI $\dagger$ ): $\delta_{\mathrm{C}} 14.50,21.75,35.60,55.73,113.63,123.89$, 127.80, 128.85, 130.22, 130.99, 133.50, 136.98, 139.95, 196.39.

\section{Synthesis of probe 1}

Compound 2 (0.1755 g, $0.5 \mathrm{mmol})$, and compound 3 (0.121 g, $0.5 \mathrm{mmol}$ ) were dissolved in $10 \mathrm{~mL}$ ethanol. The mixture was 
refluxed for 3 hours at $80{ }^{\circ} \mathrm{C}$ and cooled to room temperature. The final product 1 was obtained by filtration and being washed with ethanol for three times $(0.1404 \mathrm{~g}, 0.25 \mathrm{mmol}, 50 \%)$. Characterization of 1: HRMS (EI) $m / z$ : calcd for $\mathrm{C}_{30} \mathrm{H}_{31} \mathrm{~N}_{2} \mathrm{O}_{2} \mathrm{I}$ [M - I], 451.2380; found, 451.2385. ${ }^{1} \mathrm{H}$ NMR (400 MHz, DMSO- $d_{6}$, TMS) (Fig. S14 in ESI $\dagger$ ): $\delta_{\mathrm{H}} 8.87(\mathrm{~s}, 1 \mathrm{H}), 8.43(\mathrm{~d}, 1 \mathrm{H}), 8.37(\mathrm{~d}, 1 \mathrm{H})$, 8.27 (d, 1H), 8.21 (d, 1H), $8.09(\mathrm{~d}, 1 \mathrm{H}), 7.87(\mathrm{~s}, 1 \mathrm{H}), 8.27$ (d, 1H), $7.80(\mathrm{t}, 1 \mathrm{H}), 7.70(\mathrm{t}, 1 \mathrm{H}), 7.62(\mathrm{~d}, 1 \mathrm{H}), 6.94(\mathrm{~m}, 1 \mathrm{H}), 6.73(\mathrm{~d}, 1 \mathrm{H})$, $4.12(\mathrm{~s}, 3 \mathrm{H}), 3.57(\mathrm{~m}, 4 \mathrm{H}), 2.00(\mathrm{~s}, 6 \mathrm{H}), 1.19(\mathrm{t}, 6 \mathrm{H}) .{ }^{13} \mathrm{C}$ NMR $(100$ MHz, DMSO- $d_{6}$ ) (Fig. S15 in ESI $\dagger$ ): $\delta_{\mathrm{C}} 12.96,26.16,34.69,45.29$, 53.49, 97.04, 109.82, 110.32, 111.71, 112.77, 113.54, 123.54, 127.22 , 127.30, 128.79, 130.49, 131.26, 132.69, 133.36, 137.80, 139.98, 148.48, 150.08, 154.26, 157.98, 159.99.

\section{Conclusions}

In summary, we here developed a novel multi-mode fluorescent probe for determination of hydrazine in aqueous solution. The probe 1 could detect hydrazine based on the nucleophilicity of hydrazine. And this probe displayed high selectivity and sensitivity toward hydrazine, with a color change from blue to pale yellow by the naked eye. Probe $\mathbf{1}$ exhibited a good linear relationship between hydrazine concentration and the ratiometric fluorescence enhancement in concentration range of 0-400 $\mu \mathrm{M}$ and the LOD could be as low as $560 \mathrm{nM}$.

\section{Acknowledgements}

This work was supported by "the Fundamental Research Funds for the Central Universities (2015XKZD08)".

\section{Notes and references}

1 J. Sanabria-Chinchilla, K. Asazawa, T. Sakamoto, K. Yamada, H. Tanaka and P. Strasser, J. Am. Chem. Soc., 2011, 133, 54255431.

2 T. Sakamoto, K. Asazawa, J. Sanabria-Chinchilla, U. Martinez, B. Halevi, P. Atanassov, P. Strasser and H. Tanaka, J. Power Sources, 2014, 247, 605-611.

3 A. Serov, M. Padilla, A. J. Roy, P. Atanassov, T. Sakamoto, K. Asazawa and H. Tanaka, Angew. Chem., Int. Ed., 2014, 53, 10336-10339.

4 A. D. Sutton, A. K. Burrell, D. A. Dixon, E. B. Garner, J. C. Gordon, T. Nakagawa, K. C. Ott, P. Robinson and M. Vasiliu, Science, 2011, 331, 1426-1429.

5 R. Ahmad, N. Tripathy, D. U. J. Jung and Y. B. Hahn, Chem. Commun., 2014, 50, 1890-1893.

6 S. D. Zelnick, D. R. Mattie and P. C. Stepaniak, Aviat., Space Environ. Med., 2003, 74, 1285-1291.

7 T. Tang, Y. Q. Chen, B. S. Fu, Z. Y. He, H. Xiao, F. Wu, J. Q. Wang, S. R. Wang and X. Zhou, Chin. Chem. Lett., 2016, 27, 540-544.

8 Y. Qian, J. Lin, L. J. Han, L. Lin and H. L. Zhu, Biosens. Bioelectron., 2014, 58, 282-286.

9 A. Umar, M. M. Rahman, S. H. Kim and Y.-B. Hahn, Chem. Commun., 2008, 166-168.
10 E. Gionfriddo, A. Naccarato, G. Sindona and A. Tagarelli, Anal. Chim. Acta, 2014, 835, 37-45.

11 J.-A. Oh, J.-H. Park and H.-S. Shin, Anal. Chim. Acta, 2013, 769, 79-83.

12 L. Cui, K. Jiang, D. Q. Liu and K. L. Facchine, J. Chromatogr. A, 2016, 1462, 73-79.

13 D. S. Kosyakov, A. S. Amosov, N. V. Ul'yanovskii, A. V. Ladesov, Y. G. Khabarov and O. A. Shpigun, J. Anal. Chem., 2017, 72, 171-177.

14 G. Dutta, S. Nagarajan, L. J. Lapidus and P. B. Lillehoj, Biosens. Bioelectron., 2017, 92, 372-377.

15 R. Gupta, P. K. Rastogi, V. Ganesan, D. K. Yadav and P. K. Sonkar, Sens. Actuators, B, 2017, 239, 970-978.

16 F. A. Harraz, A. A. Ismail, S. A. Al-Sayari, A. Al-Hajry and M. S. Al-Assiri, Sens. Actuators, B, 2016, 234, 573-582.

17 J. Wu, T. Zhou, Q. Wang and A. Umar, Sens. Actuators, B, 2016, 224, 878-884.

18 B. Fang, C. H. Zhang, W. Zhang and G. F. Wang, Electrochim. Acta, 2009, 55, 178-182.

19 H. Zhang, R. Liu, J. Liu, L. Li, P. Wang, S. Q. Yao, Z. Xu and H. Sun, Chem. Sci., 2016, 7, 256-260.

20 H. Chen, Y. Tang, M. Ren and W. Lin, Chem. Sci., 2016, 7, 1896-1903.

21 Y. Tang, X. Kong, A. Xu, B. Dong and W. Lin, Angew. Chem., Int. Ed., 2016, 55, 3356-3359.

22 W. Xu, Z. Zeng, J.-H. Jiang, Y.-T. Chang and L. Yuan, Angew. Chem., Int. Ed., 2016, 55, 13658-13699.

23 R. Zhang, J. Zhao, G. Han, Z. Liu, C. Liu, C. Zhang, B. Liu, C. Jiang, R. Liu, T. Zhao, M.-Y. Han and Z. Zhang, J. Am. Chem. Soc., 2016, 138, 3769-3778.

24 W. Chen, A. Pacheco, Y. Takano, J. J. Day, K. Hanaoka and M. Xian, Angew. Chem., Int. Ed., 2016, 55, 9993-9996.

25 W. Zhou, Y. Cao, D. Sui and C. Lu, Angew. Chem., Int. Ed., 2016, 55, 4236-4241.

26 A. K. Steiger, S. Pardue, C. G. Kevil and M. D. Pluth, J. Am. Chem. Soc., 2016, 138, 7256-7259.

27 X. Wu, L. Li, W. Shi, Q. Gong and H. Ma, Angew. Chem., Int. Ed., 2016, 55, 14728-14732.

28 T. Pinkert, D. Furkert, T. Korte, A. Herrmann and C. Arenz, Angew. Chem., Int. Ed., 2017, 56, 2790-2794.

29 W. Shao, G. Chen, A. Kuzmin, H. L. Kutscher, A. Pliss, T. Y. Ohulchanskyy and P. N. Prasad, J. Am. Chem. Soc., 2016, 138, 16192-16195.

30 H. Shao, F. Wei, B. Wu, K. Zhang, Y. Yao, S. Liang and S. Qin, RSC Adv., 2016, 6, 4271-4279.

31 Y. Shiraishi, M. Nakamura, K. Yamamoto and T. Hirai, Chem. Commun., 2014, 50, 11583-11586.

32 X. Lv, J. Liu, Y. Liu, Y. Zhao, Y.-Q. Sun, P. Wang and W. Guo, Chem. Commun., 2011, 47, 12843-12845.

33 M. H. Lee, B. Yoon, J. S. Kim and J. L. Sessler, Chem. Sci., 2013, 4, 4121-4126.

34 L. Cui, Z. Peng, C. Ji, J. Huang, D. Huang, J. Ma, S. Zhang, X. Qian and Y. Xu, Chem. Commun., 2014, 50, 1485-1487.

35 D. Zhou, Y. Wang, J. Jia, W. Yu, B. Qu, X. Li and X. Sun, Chem. Commun., 2015, 51, 10656-10659.

36 M. Sun, J. Guo, Q. Yang, N. Xiao and Y. Li, J. Mater. Chem. B, 2014, 2, 1846-1851. 
37 K. Vijay, C. Nandi and S. D. Samant, RSC Adv., 2014, 4, 30712-30717.

38 S. I. Reja, N. Gupta, V. Bhalla, D. Kaur, S. Arora and M. Kumar, Sens. Actuators, B, 2016, 222, 923-929.

39 M. G. Choi, J. O. Moon, J. Bae, J. W. Lee and S. K. Chang, Org. Biomol. Chem., 2013, 11, 2961-2965.

40 Y. Sun, D. Zhao, S. Fan and L. Duan, Sens. Actuators, B, 2015, 208, 512-517.

41 Q. Zhai, W. Feng and G. Feng, Anal. Methods, 2016, 8, 58325837.

42 J. Wu, B. Kwon, W. Liu, E. V. Anslyn, P. Wang and J. S. Kim, Chem. Rev., 2015, 115, 7893-7943.

43 Z. Li, X. Liu, W. Zhao, S. Wang, W. Zhou, L. Wei and M. Yu, Anal. Chem., 2014, 86, 2521-2525.

44 M. Lan, J. Wu, W. Liu, W. Zhang, J. Ge, H. Zhang, J. Sun, W. Zhao and P. Wang, J. Am. Chem. Soc., 2012, 134, 66856694.

45 J. Fan, M. Hu, P. Zhan and X. Peng, Chem. Soc. Rev., 2013, 42, 29-43.

46 J. Fan, W. Sun, M. Hu, J. Cao, G. Cheng, H. Dong, K. Song, Y. Liu, S. Sun and X. Peng, Chem. Commun., 2012, 48, 8117-8119.

47 C. Hu, W. Sun, J. Cao, P. Gao, J. Wang, J. Fan, F. Song, S. Sun and X. Peng, Org. Lett., 2013, 15, 4022-4025.
48 S. Goswami, S. Paul and A. Manna, New J. Chem., 2015, 39, 2300-2305.

49 S. Goswami, K. Aich, S. Das, S. B. Roy, B. Pakhira and S. Sarkar, RSC Adv., 2014, 4, 14210-14214.

50 S. Goswami, S. Paul and A. Manna, RSC Adv., 2013, 3, 1887218877.

51 S. Goswami, S. Das, K. Aich, D. Sarkar and T. K. Mondal, Tetrahedron Lett., 2014, 55, 2695-2699.

52 S. Goswami, S. Das, K. Aich, B. Pakhira, S. Panja, S. K. Mukherjee and S. Sarkar, Org. Lett., 2013, 15, 54125415.

53 D. Oushiki, H. Kojima, T. Terai, M. Arita, K. Hanaoka, Y. Urano and T. Nagano, J. Am. Chem. Soc., 2010, 132, 2795-2801.

54 C. Zhao, X. Zhang, K. Li, S. Zhu, Z. Guo, L. Zhang, F. Wang, Q. Fei, S. Luo, P. Shi, H. Tian and W.-H. Zhu, J. Am. Chem. Soc., 2015, 137, 8490-8498.

55 K. Xiang, S. Chang, J. Feng, C. Li, W. Ming, Z. Liu, Y. Liu, B. Tian and J. Zhang, Dyes Pigm., 2016, 134, 190-197.

56 M. Li, W. Feng, H. Zhang and G. Feng, Sens. Actuators, B, 2017, 243, 51-58.

57 Q. Zhang, Y. Zhang, S. Ding, H. Zhang and G. Feng, Sens. Actuators, B, 2015, 211, 377-384.

58 H. Zhang, Z. Huang and G. Feng, Anal. Chim. Acta, 2016, 920, 72-79. 